\title{
Aisthesis
}

Firenze University Press

www.fupress.com/aisthesis

OPEN ACCESS

Citation: M. Landi (2021) «Les membres et la roue». À propos de Coronation de Michel Deguy. Aisthesis 14(1): 7-14. doi: 10.36253/Aisthesis-12835

Copyright: (c) 2021 M. Landi. This is an open access, peer-reviewed article published by Firenze University Press (http://www.fupress.com/aisthesis) and distributed under the terms of the Creative Commons Attribution License, which permits unrestricted use, distribution, and reproduction in any medium, provided the original author and source are credited.

Data Availability Statement: All relevant data are within the paper and its Supporting Information files.

Competing Interests: The authors have declared that no competing interests exist.

\section{«The limbs and the wheel»: about Coronation by Michel Deguy}

\author{
«Les membres et la roue». À propos de Coronation de Michel \\ Deguy
}

Michela LANDI
University of Firenze (Italy)
michela.landi@unifi.it

Je suis les membres et la roue!

(Charles Baudelaire, L'Heautontimorouménos)

Si l'on s'en tient à Ferdinand de Saussure il n'y a, à l'origine de toute chose, que le fonctionnement (Meschonnic [2008]: 423). Semblablement, le fait de se demander d'abord «à quoi ça ressemble» (Deguy [1987]: 42) est, selon Deguy, la tâche principale de la poésie. Contrairement à l'attitude la plus courante dans la communication linguistique où la question, déproblématisée, coïncide avec sa réponse, il s'agit de mettre en œuvre, avec Michel Meyer, une constante re-problematisation du procès linguistique et, par conséquent, cognitif (Deguy [1987]: 42). Remonter au mouvement de la parole qui cherche sa chose manipulant son signifiant et le forçant ainsi à secréter sa causalité interne est à notre sens l'un des enjeux les plus marquants de la poétique de Michel Deguy.

La notion d'«hésitation prolongée entre le son et le sens» empruntée à Paul Valéry (Valéry [1941]: 636), que Deguy aime souvent à citer, peut être considérée comme l'expression même du statut interrogatif, éminemment suspensif, caractérisant le rapport entre les mots et les choses; rapport sur lequel Foucault bâtit plus tard, comme on sait, une "archéologie des sciences humaines" (Foucault [1966]). Un tel statut est dû, aux yeux de Deguy, au fait que la contenance, autrement dit la forme, censée assurer et attester la présence d'un contenu donné dans un poème donné, est constamment traversée et décomposée - décontenancée - par la poésie, puissance toujours exorbitante par rapport à l'espace confiné du texte: 
Ça peut commencer par une figure [...], une tournure de la langue qui se met en ses atours, se tournant et contournant et chantournant précieusement. Le sujet vit dans sa langue et de sa langue, porté et emporté dans cette rumeur (Deguy [1987]: 44).

Le rythme (rhume de rheuma, «flux»), en tant que principe fondatif du fait poétique, est, de luimême, douleur et remède, pathos et catharsis. Étant donné la «coextension, pour ne pas dire la synonymie, du phénoménal et du rythmique» (Deguy [1987]: 44), Deguy considère «le pathos comme une pulsation, un rythme, dont l'avancée est la 'pitié' et le recul la 'terreur'» (Deguy [1987]: 45). Dans cette alternance, dont le sac et le ressac de la mer nous offrent l'exemple, réside (selon Isocrate) l'antidosis: ce «donner contre» qui, obtenu par parthénogénèse de ses composants internes ${ }^{1}$, retombe et se fixe dans l'«antidote»:

L'aspect d'une chose? [...] lêtre du "dedans», ou le-plus-au-dedans du dedans se scinde - et cette oppugnance intime constitue son essence ou valence semantique [...] - et réciproquement, "antidotiquement» (Deguy [1987]: 111).

Dans la revue qu'il a lui-même fondée en 1977, Poßsie, Deguy publiait le 13 mars $2020^{2}$, au début de l'ère de la pandémie de Coronavirus, un de ses «billets», sous le titre de Coronation. Ce terme, usité en moyen français et aujourd'hui désuet, répond de la manière la plus efficace à ce labeur de re-semantisation et re-fonctionnalisation étymologique du langage qui lui est propre. Au nom de la «langue étymologiquement néologisante» (Deguy [1987]: 35), il s'agit de «disjoindre et de conjoindre [...] pour ajointer des choses» (Deguy [1987]: 42); autrement dit, décomposer et recomposer les noms dans leurs constituants morphologiques (morphèmes, syllabes, préfixes, infixes, suffixes), de les plier et les déplier, selon la tradition mallarméenne. Dans le cadre d'un va-et-vient entre «paléonymie» et «néonymie» (selon, cette

\footnotetext{
${ }^{1}$ Cf. à ce sujet: Deguy (1981).

${ }^{2}$ https://po-et-sie.fr/chroniques/coronation/. Consulté le 7 avril 2021.
}

fois, la terminologie derridienne désormais entrée dans l'usage courant) le mot thématique coronation, qui se compose d'un substantif (corona) et d'un suffixe d'action (lat. -atio/-ationis), est mis en relation de substitution avec son allomorphe «couronnement», valant pour «sacre». Le jeu polyptotique qui se produit entre les deux mots rend compte du combat herméneutique que la poésie performative de Deguy engage avec la tradition: le paléonyme supplante et supplée le néonyme, renversant ainsi la relation d'appartenance. Lancien est, autrement dit, plus nouveau que le nouveau... En tant que «nom d'action», le déverbatif coronation atteste, en plus, de la présence concomitante de la dosis (le don, le donner) et de l'antidosis (le contre-don, ou donner-contre): celui qui gagne le combat nomme l'autre, et le découronne. Face, alors, à ce coronavirus «réel» autant que «royal», il fallait trouver l'antidote: à chaque couronne, son découronnement.

Si le nom est un destin (nomen-omen, comme on sait), le fait de varier le nom, d'en manipuler le faste, équivaut à se jouer du destin lui-même; à prendre sa revanche contre le tout-venant. Face à la réalité des choses, qui toujours nous découronne, c'est la réalité du nom qui triomphe: jubilatoire prise de pouvoir, recouronnement du détrôné. D'ailleurs, la pratique culturelle consistant à dompter l'indomptable est bien connue: tous les cataclysmes ont leur petit nom, ont leur couronne de circonstance. La résection, ou ablation d'une section du mot (ce que la science fait à la chose) dans l'espoir d'en triompher par l'antidote, est, elle aussi, à la une: les anglais nommant, par aphérèse, rona le corona, lui coupent, sans le vouloir, la tête. Mais ce n'est pas tout: par une erreur de déglutination assez significative, la censure sociale des anglais puritains s'attache inopinément au faux préfixe co-, marquant ainsi la contaminante compagnie entre l'homme et la chose...

Et pourtant, à plus d'un an de distance de la publication de Coronation de Deguy, nous sommes encore encerclés, contaminés, par les variantes morphologiques de la maudite couronne. Au moment où nous divaguons, l'hôte obscur se transforme, se déguise incessamment par 
ses menus constituants: l'antidote tarde à s'affirmer, à se donner-contre.

La contamination est, d'ailleurs, le procédé même permettant la création. Si l'on se réclame de la doctrine émanatiste de Plotin, ou procession (ex uno plures), Dieu crée le monde à partir de sa propre substance, inépuisable, qui se multiplie et se développe, ainsi que se développent, par parthénogénèse, les organismes vivants. La pensée logique elle-même fonctionne par émanation, ou déduction: c'est de la «couronne» première que descendent les "corollaires». Dans le cadre de la doctrine émanatiste, instituant la chaîne des êtres par supplémentarité, la femme ne serait, selon les Proverbes (12, 4-5), que l'émanation de l'homme: émanant de l'émané, "corona viro suo». Corona viro? L'histoire enseigne: la couronne est polytrope, elle contemple autant le don que le contre-don, autant l'actif que le passif, et le couronnement est gloire et martyre à la fois. De même, l'auréole est, selon Saint Bonaventure (Breviloquium VII, 7, 5), la marque d'un contre-don: c'est à la suite d'un sacrifice qu'elle confère au corps sa plénitude. Dans le Livre de Job $(31,35-36)$ il est dit que le Livre écrit par celui qui juge doit être porté sur ses épaules, et doit entourer la tête de son témoin tel une couronne. Ainsi, en vertu de sa circularité formelle et symbolique la couronne a, comme le sacré dont elle se fait l'expression, deux faces: celle du mandant et celle du mandataire.

Dans une fresque funèbre du XVe siècle on voit un squelette assis sur un trône d'or qui s'aliène, par des coups de pied, les prédicats positifs qui l'entourent: mitres, couronnes, livres, globe terrestre. Sa tête est appuyée sur sa main déssechée, cherchant à soutenir une couronne vacillante. C'est l'une des nombreuses vanités qui peuplent Les Fleurs du mal de Baudelaire. Dans Le Masque (Baudelaire [1861]: 23) «chaque trait» du «visage mignard, tout encadré de gaze» invite le poète à prononcer "avec un air vainqueur» ce magnifique alexandrin: «La Volupté m’appelle et l'Amour me couronne!».

\footnotetext{
${ }^{3}$ «Mulier diligens corona est viro suo, et quasi putredo in ossibus eius, quae est inhonesta».
}

Cette autocitation si menaçante, dûment encerclée, isolée, réifiée par les guillemets, est d'elle-même un couronnement ironique de la part du poète. De même, dans Une gravure fantastique, le "diadème affreux sentant le carnaval» (Baudelaire [1861]: 69) se reclamerait d'un témoignage de Villeneuve-Bargemont (1424), concernant une danse macabre: "épouvantable divertissement auquel présidait un squelette ceint du diadème royal et assis sur un trône resplendissant de pierreries» (Richter [2003]: 203). Ainsi Baudelaire nous montrerait du doigt, une fois de plus, l'auréole de la gloire poétique souillée, déchue et dégradée, si l'on se souvient de Perte d'auréole (Baudelaire [1868]: 352). C'est, justement, de ce poème en prose que se réclame Walter Benjamin pour constater la perte 'auratique' de l'objet suite à son déplacement, à sa mobilité et, finalement, à sa contamination par l'industrie (Benjamin [1936]: 28). Baudelaire aime, d'ailleurs, à se défaire des attributs du poète couronné, en se peignant volontiers comme l'émanation pestilentielle du dessein divin exécuté par la Mère (Bénédiction, Baudelaire [1861]: 7-9). Les «boutons empestés» de cette descendance seront tressés néanmoins en de nouvelles couronnes dans Je te donne ces vers (Baudelaire [1861]: 40):

\section{[...] il faut pour tresser ma couronne mystique Imposer tous les temps et tous les univers.}

Stéphane Mallarmé, tout admiratif qu’il était des épigrammes licencieuses composant la Couronne (stephanos) de Méléagre de Gadara (l'étymon stephanos étant déjà attesté chez Homère: Iliade, VIII, v. 597), devait connaître le Peri stephanon de Prudence, qui compte parmi les traités les plus célèbres de la martyrologie chrétienne. C'est justement Stéphane, le premier martyr, qui prend, par éponymie, le nom de la "couronne» dont on lui ceint la tête: se repropose en effet, en milieu chrétien, la valeur sacrificielle de la couronne de laurier (Daphné poursuivie par Apollon, s'enfuit en se transfigurant dans la plante qui devient, pour le poète, la marque même de la douleur poétique; thème que Dante et Pétrarque auront repris 
à leur compte). La topique médiévale du bois amer avec lequel on tresse la couronne des poètes revient chez Mallarmé: c'est de Dante que se réclame le "laurier amer» de Contre un poète parisien (Mallarmé [1862]: 20) ${ }^{4}$. Paul Valéry s'en souviendra dans le Cimetière marin, évoquant la mort en tant que "consolatrice affreusement laurée» (Valéry [1920]: 150]) ${ }^{5}$. Se rémémorant l'exemple baudelairien, Mallarmé évoque, à titre d'équivalent du nom, l'horrible diadème d'Hérodiade (Mallarmé [1887]: 42) qui se réflète dans son miroir: don contre don, nom contre vie. Ainsi, dans La chevelure, vol d'une flamme (Mallarmé [1887]: 53):

\section{La chevelure vol d'une flamme à l'extrême} Occident de désirs pour la tout déployer Se pose (je dirais mourir un diadème) Vers le front couronné son ancien foyer.

Le nom «diadème», déverbatif de diadeo ("ceindre la tête par un fil»), est un mot-thème qui se dissémine dans l'espace du texte par le biais de ses constituants morphologiques, formant ainsi un réseau paragrammatique: le morphème phonolexical -diade évoque, à lui seul, le lien à double fil donnant le mot d'Hérodiade (héroïne morte-vivante, écrasée par le poids symbolique de son nom) [Mallarmé 1887: 45-46], ou, par anagramme, l'Idumée évoqué dans Don du poème (Mallarmé [1887]: 40) ${ }^{6}$, ou bien encore le thème suffixal déverbatif -ème si récurrent chez Mallarmé. Au «diadème», remplaçant du nom du poète, s'associent d'autres prédicats d'identité, tels la «guirlande» d'Une dentelle s'abolit (Mallarmé [1887]: 74):

Cet unanime blanc conflit

D'une guirlande avec la même,

Enfui contre la vitre blême

Flotte plus qu'il n'ensevelit.

\footnotetext{
${ }^{4}$ «Dante, au laurier amer, dans un linceul se drape,/Un linceul fait de nuit et de sérénité»

5 «Maigre immortalité noire et dorée,/Consolatrice affreusement laurée,/Qui de la mort fais un sein maternel,/Le beau mensonge et la pieuse ruse!/Qui ne connaît, et qui ne les refuse,/Ce crâne vide et ce rire éternel!»

${ }^{6}$ Voir à ce sujet: Saurat (1931).
}

Ce quatrain rend compte, autant que faire se peut, du combat herméneutique entre la dosis et l'antidosis, entre le don et le contre-don qui fait le lot du poète-martyr; on se souvient une fois de plus d'Hérodiade se regardant dans son miroir nocturne. De même, dans Le Cimetière marin (Valéry [1920]: 149) Valéry reprend le thème du martyre du poète, "affreusement lauré», dans ces termes:

Tête complète et parfait diadème,

Je suis en toi le secret changement.

Une variante hypocoristique de "couronne», «corolle» (<coronula), évoque, par synecdoque, la fleur dont l'effusion peut être, à la fois, baume et poison, dot et antidote. Dans L'automne de Lamartine (Lamartine [1820]: 76), la corolle qui se détache de sa tige (qui, autrement dit, abandonne son 'lieu') répand autour d'elle un parfum mortifère, aura pestilentielle:

La fleur tombe en livrant ses parfums au zéphire;

[...]

Moi, je meurs; et mon âme, au moment quelle expire,

Sexhale comme un son triste et mélodieux.

Dans un texte successif, La cloche du village (Lamartine [1839]: 1161), les cloches sont, par métonymie, autant de corolles attachées à leur tige, le clocher; sauf que la force centrifuge du mouvement provoque le détachement de l'objet de son tronc et la dissémination mortifère de cet appel7. C'est donc une fois de plus, semble-t-il, l'abandon du 'lieu', et l'ubiquité 'auratique' de la corolle qui provoque le désastre: l'effet, s'émancipant de sa cause, contamine l'espace circonstant d'une odeur fétide. De même, la guirlande se défait au crépuscule de la vie, pour un festin mortifère:

Guirlandes du festin que pour un soir on cueille, Que la haine empoisonne ou que l'envie effeuille,

${ }^{7}$ «Quand du clocher vibrant l'hirondelle habitante/S’envole au vent d'airain qui fait trembler sa tente,/Et de létang ridé vient effleurer les bords...» 
Dont vingt fois sous les mains la couronne se rompt, Qui donnent à la vie un moment de vertige, Mais dont la fleur d'emprunt ne tient pas à la tige, Et qui sèche en tombant du front.

Des «boutons empestés» de Bénédiction (Baudelaire [1861]: 7), à Harmonie du soir (Baudelaire [1861: 47] où, on s'en souvient, «Les sons et les parfums tournent dans l'air du soir», à Le Jet d'eau (Baudelaire [1861]: 160), où la «gerbe épanouie/en mille fleurs» est associée à la plainte sanglotante de la fontaine de vie qui «tombe comme une pluie/De larges pleurs», c'est la dissolution du mot-thème, et son expansion-exhalaison qui provoque, chez Baudelaire, le désastre. Semblablement, dans Les Fleurs de Mallarmé (Mallarmé [1887]: 33) la terre innocente, encore «vierge de désastres», est fécondée par des fleurs pestilentielles qui, se détachant de leur tige, infestent le monde de leurs néfastes réplications. La corolle, calice sacré dont on s'abreuve dans l'innocence ${ }^{8}$, est détachée de sa matrice par la volonté de la Mère qui, corona viro suo, exerce fidèlement et dans la même innocence la loi trascendante du Père:

Ô Mère qui créas en ton sein juste et fort,

Calices balançant la future fiole

De grandes fleurs avec la balsamique Mort

Pour le poète las que la vie étiole.

Déversée et répandue sur la terre vierge, la «future fiole» (hommage au Flacon baudelairien: Baudelaire [1861]: 47) provoque la calamité:

\section{Jadis tu détachas les grands calices pour}

La terre jeune encore et vierge de désastres.

Car l'initié, selon le mot en écho de Valéry (La Jeune Parque [1927]: 96), a bien «soif de désastres»...

L'encre est souvent l'équivalent matériel de cette perfide dissémination; efflorescence d'une raison séminale, la plûme sécrète la maladie, en essayant de la «contenir» dans une forme cir-

\footnotetext{
${ }^{8}$ Voir aussi, à ce sujet, Les colchiques d'Apollinaire dans Alcools (Apollinaire [1913]:33)
}

culaire, couronne ou guirlande: glose autour du nom (selon la tradition, chère aux Grands Rhétoriqueurs, des couronnes serties, ou des chapelets égrénés autour des Noms vénérés). Une fois de plus, la plûme est le mal et le rémède à la fois: elle fait et défait la definitio nominis, fait et défait la mort: "Noirs vols du Blasphème épars dans le futur» écrit Mallarmé dans le Tombeau d'Edgar Poe (Mallarmé [1887]: 70). Tombant comme de la pluie fécondante sur la page vierge, tellus inarata, l'encre, nominatis rebus destructis, 'décompose' (décontenance, dirait Deguy) ce qui est 'composé' (contenancé) pour la mort: le signe hiératique devient erratique. Ainsi, le poème est une couronne de mots incessamment sertie et dessertie...

C'est par une ironie goguenarde que Deguy s'attaque à la menace de la dernière couronne. Dans Coronation, le signifiant coronavirus est, dès l'incipit, exhibé dans toute sa majesté, dans ses pompes royales: sa stature pentasyllabique est bel et bien entourée de son apparat consonantique: la consonne vélaire d'attaque, $/ k /$; la vibrante et belliqueuse $/ r /$ qui, on le sait, appelle à l'action militaire; la rude consonne fricative labiodentale sonore $/ v /$, et, finalement, la perfide sibilante qui, en position finale, dissémine autour d'elle sa sonorité néfaste. Comment ne pas penser au serpent couronné, qui, venant de très loin, hante l'imaginaire des poètes? Et pourtant le nom royal, le mot-thème, est, comme c'était le cas plus haut à propos de Baudelaire, dûment contenancé par de politiques guillemets, qui tentent de préserver l'espace circonstant contre les funestes réplications du mal. Les guillemets ont donc une double fonction antidotique: tout en isolant le mot-thème, elles le défonctionnalisent, et le condamnent à sa pure virtualité sonore, le privant ainsi de son pouvoir de contamination factuelle: nomina nuda tenemus. Cette action de contenance est doublée par l'article défini qui, entre temps, s'approprie la chose en la nommant (nommer, on le sait, c'est dompter). Ce trophée, ce monstre ainsi apprivoisé par la nomination forme, de par ses six syllabes, une hémistiche facile. Mais voici la seconde hémistiche qui, faisant preuve d'une force rythmique égale et contraire à la première, en contreba- 
lance la toute-puissance: donnant-donnant, selon une expression chère à Deguy (Deguy [1981]), ou nommant-nommant. Les deux ennemis en miroir - une guirlande avec la même, dirait Mallarmé forment, ainsi, l'alexandrin attendu. Le nom-roi, ridiculisé, carnavalisé, va être glosé et «cadencé» (cadenassé ?); la satire pactise avec la mort.

Selon la loi de causalité ou motivation interne, la "contamination» provient de "Contamines", toponyme suisse, savoyard: ses habitants sont appelés, par malheur, «contaminards»...; mais l'étymon nous fait remonter plutôt à condominium (domaine commun). Bref, le jeu paronymique entre contaminare et condominare pourrait suggérer que c'est bien la cohabitation globale la cause principale de la co-morbidité... En effet, si ce qui est fait ne cesse de se défaire, les confins ne cessent de se déconfiner: le dedans se renverse et se déverse dans son dehors. Le dédoublement, ou réplication par parthénogénèse, du pronom inclusif («nousnous») rend ce dernier réflexif attestant que nous, miroirs de nous-mêmes, ou nous-mêmes au miroir comme Hérodiade, nous ne faisons que nous entregloser (Montaigne), à savoir, nous contaminer... car nous sommes, de chaque phénomène, la cause et l'effet à la fois. En même temps que la perte sonore du mot mortifère est associée (thème très mallarméen) à la perte boursière, la «perte de face» des asiatiques en tant qu'«infecteurs» du monde peut soit s'étendre, par métonymie, au monde entier, soit se décliner, par syllepse, au sens propre et au sens figuré: une fois de plus, nous avons la dosis et l'antidosis, car le masque protégeant le visage contre l'atteinte du virus n'est que le revers de l'écran contre lequel ce visage même s'écrase: simulacre contre simulacre, museau contre museau, le masque et l'écran s'affrontent comme dans les combats de chiens si vantés par la Chine. D'ailleurs, d'une telle éthologie font preuve les souverains noms gouvernant (couronnant) le monde: du négationnisme mis en avant par le molosse trumpien jusqu'à la régression putinienne vers une religiosité fondée sur la superstition, ou la clôture lépénienne des confins nationaux, alors que le premier ministre anglais fait de sa Victoria (par syllepse: la gare de Londres par antonomase, et son succès politique) une gloire postiche, nouvelle Singapour... l'impérialisme, dans les deux sens, serait une contamination parmi d'autres.

Par la même loi, la consommation touristique («croisières») porte en elle-même sa croix: le dénominatif néologique «s'enquarantainer», à valeur causative et réfléxive, atteste la coïncidence entre le moment actif et le moment passif de l'action, entre sujet couronnant et sujet couronné, entre mandant et mandataire...du virus: c'est par un autre néologisme sylleptique, "covirés» (indiquant à la fois le partage de la maladie et le confinement dont les malades ont fait l'objet), que le dehors est maintenant renversé dans son dedans. C'est grâce à ce confinement - la quarantaine dans les ports («à quai») - que Venise, destination touristique de masse, contaminée de toutes parts et contaminante elle aussi en raison de ses eaux, est finalement - par une métaphore empruntée à la tradition biblique, et notamment musaïque - «sauvée des eaux». Une coïncidence temporelle avec l'avancée du virus justifie cette syllepse: le barrage connu sous le nom de MOSE (acronyme pour: «Module expérimental électromécanique») est soulevé pour la première fois suite à un débordement, préservant ainsi la ville de l'énième inondation. Venise connaît ainsi le même destin que Moïse, son paronyme: elle est "sauvée des eaux». À noter ensuite le fait que la labiodentale sonore $/ v /$ initiale de virus et de Venise, se trouvant en position prosthétique, transforme l'«eau» de Venise en "veau» de Venise: la ville, veau d'or du tourisme (en raison, souvent, de l'imaginaire décadent l'associant à la maladie) est, tout à la fois, la cause et l'effet du virus et du barrage qui l'en préserve.

La référence à l'actualité se repropose par d'autres concomitances spatio-temporelles: le premier tour des «Municipales» de 2020 en France a eu lieu le 15 mars, en plein essor du virus. Cinq jours avant la date vraie ou présumée de rédaction de ce texte, le 20 mars 2020, le mouvement Europe Ecologie-Les Verts (EELV) obtient un succès inattendu, confirmé au second tour; le virus y était-il pour quelque chose? D'où, en tout cas, l'occurrence du verbe programmatique, «décontenan- 
cer» qui prend, une fois de plus, deux acceptions: au sens courant, il évoque la surprise de cette affirmation politique après des décennies d'insuccès; au sens figuré, le débordement des voix qui, confinées d'abord à un espace très restreint, vont déferler, comme le virus, dans l'espace politique: de nouveau, le dedans se déverse dans le dehors. Par une métaphore cinématographique, on accuse le monde de marcher à rebours: c'est un film projeté à l'envers, antidosis. Alors que le ciel de Pékin, se déversant au dehors, régénère son dedans (son bleu, sa santé: le verbe «bleuir», causatif et dénominal, atteste l'action de régénération interne au verbe lui-même, tautologie et auto-référentialité), Paris, par contre, renouvelle sa tradition, spleen et flânerie - deux postures poétiques stéréotypées, réifiées par l'habitude - en roulant en trottinette, selon la dernière mode écolo qui vient de s'affirmer. Ici, deux poètes de la ville sont convoqués à la fois - sylleptiquement - à titre emblématique: Léon-Paul Fargue avec son Piéton de Paris (Fargue [1939]), et Deguy lui-même, auteur autonymique d'un Spleen de Paris (Deguy [2001]). À noter que l'hommage de Deguy au recueil de poèmes en prose baudelairien, Le Spleen de Paris (Baudelaire [1868]), est un acte de lèse-majesté aux conséquences salutaires: là où Baudelaire n'avait pas pu choisir le titre en question - trouvé par ses éditeurs en vue de l'édition posthume de ces poèmes épars - Deguy supprime l'article défini en coupant, à ce titre, la tête. Cette suppression, cette perte d'auréole, toute salvifique qu'elle est, ne porte pas moins en elle un effet secondaire: si, comme on l'a vu, l'article isole le nom dans l'espace, le contourne en le protégeant contre les assauts du factuel, le spleen, de fictif (de textuel) qu'il était, devient réel et royal: il se répand partout en ville en conséquence de la diffusion de l'épidémie. Car voici que défilent, sur écran (le texte faisant ici fonction d'écran) les chiffres comparés des contagions qui accompagnent, dans une sorte de match global, la vie quotidienne des «co-virés» (ceci se poursuit, entre parenthèses, au moment même où nous écrivons ce texte). La Lombardie et la Chine, ces deux antonomases de la co-viralité à son état naissant, sont citées ici à titre de comparants de circonstance; pour faire triompher l'Héxagone (qui, par concession rhétorique vient le dernier dans le texte), un seul couple adverbial antonymique: "plus/seulement», suffira pour apaiser l'opinion publique quant au bon positionnement de la France dans ce défi mondial.

Le coronavirus a occasionné tout aussi bien une mutation sémantique, voire épistémique: la «reconnaissance», substantif prédicatif multivoque en français (à valeur cognitive et morale à la fois) a délaissé le champ de la philosophie morale où il avait trouvé sa raison d'être avec, par exemple, un Lévinas (Lévinas [1961], [1991]) pour passer du côté de la médecine. Il ne s'agit plus, maintenant, que de retracer, de détecter le ADN du virus en vue de la mise à point du vaccin. Là où pandémie et mondialisation ne sont que le côté gagnant, envahissant, actif, couronnant, du monde, voici son revers: le sacrifice, le martyre. Celui-ci survient à propos des migrants qui, en dépit des confinements auxquels ils sont depuis longtemps soumis, n’arrêtent de se déconfiner et de déferler comme la vague sur nos rives: victimes du virus, et, selon quelques-uns, virus eux-mêmes, ils se répandent partout comme la maladie. Et pourtant, par la loi de l'antidote, ils sont les plus exposés à la maladie elle-même: «encoronavirés» (par syllepse: couronnés, atteints par le virus, et chassés) ils portent, en Christ "des obscures espérances» (Apollinaire [1913]: 14), la couronne du sacrifice global. Une fois de plus, selon une topique bien connue, l'argent (et nommément la "couronne", devise émanant du pouvoir royal) circule à l'aune de la maladie: semblablement au virus, qui se propage d'homme à homme atteignant des chiffres exorbitants, les 'passeurs' de Libye vers les côtes d'Europe font monter les prix: vente aux enchères au dépens des passagers.

La conclusion, provocatoire, est résolument je m'en foutiste: contre le providentialisme ambiant, tout sera comme avant. L'empereur chinois $\mathrm{Xi}$ Jinping, ayant déjà nié toute responsabilité face au virus, ôte enfin son masque. Libéré du virus qu'il est censé avoir provoqué, et le donnant en héritage au reste du monde, il met à nu son visage: le mot sinisme unit dans le même signifiant, par syllepse, 
le cynisme (dont témoigne également, nomen omen, le combat de chiens évoqué plus haut), et le nom du peuple (l'archaïque Sina, donnant le préfixe sino-) que l'empereur représente par sa couronne.

Il nous reste, note Deguy dans La Poésie n'est pas seule, «cet autovaccin homéopathique, cette catalyse et apocalypse qui ajoute au monde sa fin, qui 'précipite' sa fin, c'est la possibilité de l'art» (Deguy [1987]: 119). L'art, ajoutant toujours une fin à la fin, dévie la vie, en change le cours. Une telle restitution, par rapport à ce qui nous a été donné, est notre seul salut: «Donataires nous redonnons aux dieux par antidosis les dons échus pour notre déchéance» (Deguy [1987]: 138).

Le 15 septembre 2020 sortait un docufilm clandestin d'Ai Weiwei, chinois dissident, sur le confinement à Wuhan, portant le titre de Coronation.

\section{RÉFÉRENCES BIBLIOGRAPHIQUES:}

Apollinaire, G., 1913: Alcools, Gallimard, Paris, 1920.

Baudelaire, Ch., 1861: Les Fleurs du mal, Gallimard, Paris, Bibliothèque de la Pléiade, 1975.

Baudelaire, Ch., 1868: Le Spleen de Paris, Gallimard, Paris, Bibliothèque de la Pléiade, 1975.

Benjamin, W., 1936: Das Kunstwerk im Zeitalterseiner technischen Reproduizierbarkeit, trad. it. Lopera d'arte nell'epoca della sua riproducibilità tecnica, Einaudi, Torino, 2000.

Deguy, M., 1981: Donnant donnant, Gallimard, Paris.

Deguy, M., 1987: La poésie n'est pas seule. Court traité de poétique, Seuil, Paris.

Deguy, M., 2001: Spleen de Paris, Galilée, Paris.

Fargue, L.-P. 1939: Le Piéton de Paris, Gallimard, Paris.

Foucault, M., 1966: Les mots et les choses. Une archéologie des sciences humaines, Gallimard, Paris.

Lamartine, A. de, 1820: Méditations poétiques, in Euvres poétiques complètes, Gallimard, Paris, Bibliothèque de La Pléiade, 1963.

Lamartine, A. de, 1839: Recueillements poétiques, in Euvres poétiques complètes, Gallimard, Paris, Bibliothèque de La Pléiade, 1963.
Lévinas, E., 1961: Totalité et Infini. Essai sur l'extériorité, Kluwer, Paris.

Lévinas E., 1991: Entre nous. Essais sur le penser-àl'autre, Grasset, Paris.

Loreau, M., 1980: Michel Deguy. La poursuite de la poésie tout entière, Gallimard, Paris.

Mallarmé, S. 1862: Euvres complètes, Gallimard, Paris, Bibliothèque de la Pléiade, 1945.

Mallarmé, S., 1887: Euvres complètes, Gallimard, Paris, Bibliothèque de la Pléiade, 1945.

Meschonnic, H. 2008: Dans le bois de la langue, Laurence Teper, Paris.

Meyer, M., 1986: De la problématologie, Bruxelles, Mardaga.

Moussaron, J.-P., 1992: La Poésie comme avenir. Essai sur l'ouvre de Michel Deguy, précédé de «Syllabe», de Jacques Derrida, Le Griffon d'argile/Presses universitaires de Grenoble, SainteFoy/Grenoble.

Richter, M., 2003: Le «soleil» de la «risible Humanité». Autour d'une variante de Danse macabre, in Marchal B.; Guyaux A. (eds), Les Fleurs du mal, actes du Colloque de la Sorbonne des 10 et 11 janvier 2003, Presses de l'Université de Paris-Sorbonne, pp. 201-216.

Rueff, M., (ed.), 2007: Michel Deguy. Lallégresse pensive, Belin, Paris.

Rueff, M., 2009: Différence et identité. Michel Deguy, situation d'un poète lyrique à l'apogée $d u$ capitalisme culturel, Hermann, Paris.

Saussure, F. de, 1916: Cours de linguistique générale, Payot, Paris, 1972.

Saurat, D., 1931: La Nuit d'Idumée: Mallarmé et la Cabale, «Nouvelle Revue Française» n. 219 (1 déc.), pp. 920-922.

Valéry, P., 1920: Euvres I, Gallimard, Paris, Bibliothèque de la Pléiade, 1957.

Valéry, P., 1927: Euvres I, Gallimard, Paris, Bibliothèque de la Pléiade, 1957.

Valéry, P., 1941: Tel Quel, Euvres II, Gallimard, Paris, Bibliothèque de la Pléiade, 1960.

Volat, H.; Harvey, R., Les écrits de Michel Deguy: Bibliographie [archive], 1960-2000, IMEC, Paris, http://hvolat.com/Deguy/Deguyindex. html. Consulté le 7 avril 2021. 